\title{
A short-form version of the Boston Naming Test for language screening in dementia in a bilingual rural community in Galicia (Spain)
}

\author{
M. C. Nebreda, ${ }^{1}$ A. García-Caballero, ${ }^{1}$ E. Asensio, ${ }^{1}$ P. Revilla, ${ }^{2}$ \\ M. Rodriguez-Girondo ${ }^{1}$ and R. Mateos ${ }^{3}$ \\ ${ }^{1}$ Complexo Hospitalario de Ourense, Rúa Ramón Puga 52-54, 32005 Ourense, Spain \\ ${ }^{2}$ Misión Biológica de Galicia (CSIC), Apartado 28, 36080 Pontevedra, Spain \\ ${ }^{3}$ Department of Psychiatry, School of Medicine, E-15782, Santiago de Compostela, Spain
}

ABSTRACT

Background: Aphasia, one of the core symptoms of cortical dementia, is routinely evaluated using graded naming tests like the Boston Naming Test (BNT). However, the application of this 60 -item test is timeconsuming and shortened versions have been devised for screening. The hypothesis of this research is that a specifically designed shortened version of the BNT could replace the original 60-item BNT as part of a mini-battery for screening for dementia. The objective of this study was to design a short version of the BNT for a rural population in Galicia (Spain).

Methods: A clinic group of 102 patients including 43 with dementia was recruited along with 78 healthy volunteers. The clinic and control groups were scored on the Spanish version of the Mini-mental State Examination (MMSE) and BNT. In addition, the clinic group was tested with standard neuropsychological instruments and underwent brain investigations and routine neurological examination. BNT items with specificity and sensitivity above 0.5 were selected to compose a short battery of 11 pictures named BNTOu 11 . ANOVA and mean comparisons were made for MMSE and BNT versions. Receiver operating characteristics (ROC) curves and internal consistency were calculated.

Results: Areas under ROC curves (AUC) did not show statistically significant differences; therefore BNTOu11's AUC (0.814) was similar to the 60-item BNT versions (0.785 and 0.779), to the short versions from Argentina (0.772) and Andalusia (0.799) and to the Spanish MMSE (0.866). BNTOu11 had higher internal consistency than the other short versions.

Conclusions: BNTOu1 1 is a useful and time-saving method as part of a battery for screening for dementia in a psychogeriatric outpatient unit.

Key words: dementia, graded naming tests, aphasia, Mini-mental State Examination, rural population, bilingual, low education

\section{Introduction}

Several authors have encouraged the development of short cognitive instruments to avoid the use of comprehensive neuropsychological batteries for preliminary screening of patients potentially affected by dementia (Tombaugh and McIntyre, 1992; Feher et al., 1992). Although several shortened tests have been developed for diverse populations, tests developed for specific communities perform poorly in populations with a

Correspondence should be addressed to: Mr M. C. Nebreda, Rua do Cruceiro 17-7A, 36002 Pontevedra, Spain. Phone: +34 699863337. Email: consuelo.nebreda.vicario@sergas.es. Received 16 Apr 2010; revision requested 26 May 2010; revised version received 20 Jun 2010; accepted 20 Jun 2010. different cultural or linguistic background (GarcíaCaballero et al., 2006).

Quantitative evaluations of aphasia are usually performed by using graded naming tests (Weintraub, 2000). One of these instruments is the well-known Boston Naming Test (BNT) (Kaplan et al., 1978), a 60-item battery originally devised for assessing aphasia, but widely used for evaluating anomia in several dementias (Goodglass et al. 1998), and as a useful method to assess the evolution of the disease (Williams et al., 1989). A first 60 -item Spanish version of the BNT was proposed as a translation into Spanish from the modified version published by Goodglass and Kaplan (1986). A second modified version was proposed as a 
new translation to Spanish from Goodglass (2005). This second version has replaced the first in most settings. Hereafter we will refer to these 60 -item versions as BNT-1 and BNT-2, respectively.

Several reports have shown that the BNT efficiently discriminates healthy elderly from those with dementia (Martin and Fedio, 1983; LaBarge et al., 1986; Lansing et al., 1999; Welch et al., 1996). Nevertheless, 60 -item versions of the BNT require 15-30 minutes, time that is beyond the scope of a routine screening for dementia. In order to improve the efficiency of the test, shorter versions of the BNT have been the aim of different researchers. Williams et al. (1989) demonstrated that the BNT could be split in half ( 30 items each) with similar performance as the complete version. Later, Mack et al. (1992) observed similar performance for the four 15-item quarters of the BNT. However, the authors concluded that a reliable shortened version should be specially designed and validated for each target population. Later, Lansing et al. (1999) demonstrated the discriminating ability of the four versions proposed by Mack et al. (1992).

These short versions of BNT were devised for English-speaking communities, and therefore several items were not appropriate for populations with a different cultural background. Moreover, cultural and lexical characteristics are specific for each region or for specific groups like illiterates, bilinguals, and people living in rural environments or populations with high rates of migration. Following this rationale, Serrano et al. (2001) developed a shortened version (12 items) adapted to Argentina by choosing items that specifically distinguished patients with dementia from those without dementia in their target area. Later, Calero et al. (2002) tested the shortened version proposed by Mack et al. (1992) in southern Spain with reasonable success.

The hypothesis we tested in this study was that a specially designed shortened version of the BNT could replace the original 60 -item BNT as part of a battery for initial screening for dementia. The study objectives were therefore to design a shortened version for a rural population of low educational level in Galicia (Spain) and to compare its performance with other short versions devised for different Spanish-speaking populations in Argentina (Serrano et al., 2001) and Andalusia (Spain) (Calero et al., 2002).

\section{Methods}

A clinic group of 102 consecutive patients referred for cognitive evaluation to a psychogeriatric outpatient unit was recruited along with 78 healthy volunteers (Table 1). The clinic group included 43 patients affected by dementia following DSM-IVR criteria (American Psychiatric Association, 2000) and 59 patients who received other diagnoses, including mood disorders, anxiety disorders, and mild cognitive impairment not fulfilling DSM-IVR criteria for dementia.

Exclusion criteria were illiteracy, severe loss of visual acuity, severe hypoacusia, previous history of traumatic brain injury and active alcohol or drug dependence. Controls were excluded when MMSE score was less than 24. The clinic and control groups were assessed with the Spanish MMSE and BNT. In addition, the clinic group was examined using standard neuropsychological instruments. Furthermore, information was obtained from the relatives or people in charge regarding activities of daily living with several cognitive tasks. According to maternal language, the 180 individuals were divided into Galician speakers (114), Spanish speakers (34) and bilinguals (32). Bilingualism was assessed following a modification of the questionnaire of bilingualism included in the Spanish-Galician version of the Bilingual Aphasia Battery (BAT) (Paradis and Elias, 1989).

Both clinic and control group were studied using the following tests:

1. Spanish version of the Mini-mental State Examination (Spanish MMSE). This test was originally proposed by Folstein et al. (1975) and adapted into Spanish by Lobo et al. (1999).

2. Boston Naming Test (BNT). We used the first Spanish version of the BNT published by Goodglass and Kaplan (1986) and translated into Spanish, hereinafter called BNT-1, wherein 12 items from

Table 1. Number of individuals in the sample of elderly rural population from Ourense (Spain) used for this research

\begin{tabular}{|c|c|c|c|c|c|c|c|c|c|}
\hline \multirow[b]{2}{*}{ GROUP } & \multicolumn{2}{|c|}{ GENDER } & \multicolumn{3}{|c|}{ AGE } & \multicolumn{3}{|c|}{ LANGUAGE } & \multirow[b]{2}{*}{ TOTAI } \\
\hline & MALE & FEMALE & MEAN & MIN. & MAX. & GALICIAN & SPANISH & BILINGUAL & \\
\hline Patients with dementia & 10 & 33 & 78 & 57 & 91 & 26 & 12 & 5 & 43 \\
\hline Patients without dementia & 24 & 35 & 75 & 62 & 88 & 39 & 8 & 12 & 59 \\
\hline Control & 41 & 37 & 79 & 71 & 94 & 49 & 14 & 15 & 78 \\
\hline
\end{tabular}


the former English version of the BNT had been altered. In addition, we used another Spanish version, the BNT-2, also translated into Spanish from the modification proposed by Goodglass (2005) in which seven items from the English version were replaced by seven items in the Spanish translation (Mushroom was replaced by "Zanahoria" (carrot), Pretzel by "Magdalena" (muffin), Wreath by "Corona” (crown), Knocker by "Chupete" (pacifier), Noose by "Aguja" (needle), Latch by "Cerradura" (locker) and Trellis by "Regadera" (watering-can). Altogether, the BNT-2 differed from the BNT-1 on five items; there were therefore 55 items common to both BNT versions and five items specific to each version. Consequently, participants were shown a battery of 65 items. Each subject was asked to identify the picture in around 20 seconds and the answer was considered positive if the name was correct. If the answer was incorrect owing to a misperception or a wrong identification, a previously established semantic cue was provided with an additional 20second period to identify the object. If, after the semantic cue, the subject did not recognize the object or gave a wrong name, a phonetic cue was provided and the answer was registered for other studies. Following the procedure recommended in the Spanish translation of Goodglass (2005), for the purpose of this research the answer was considered positive if the person identified the item either spontaneously or after the semantic cue.

Specificity and sensitivity for all BNT items were calculated using SPSS software Version 17. Those items with specificity and sensitivity above 0.5 were selected to create a shortened battery of 11 pictures named BNTOu11. Analyses of variance were performed for the values of the Spanish MMSE and all BNT versions by using the GLM procedure of the Statistical Analysis Software (SAS
Institute, 2007). The ANOVA included as fixed factors gender, language, education and diagnosis, along with their interactions. Means were compared by using least square means (Steel et al. 1997). Pearson's correlations among scores of Spanish MMSE and versions of BNT were calculated with SAS Institute (2007). Receiver operating characteristics (ROC) curves, including their correspondent areas under the curve (AUC), and standard errors were calculated using SPSS for the Spanish MMSE, BNT-1, BNT-2, and the shortened versions BNT12 (Serrano et al., 2001), BNT15 (Calero et al., 2002) and BNTOu11. Curves were compared with confidence intervals, following the percentile bootstrap estimation method. Finally, internal consistency of the different BNT versions was measured by means of the Cronbach's $\alpha$ coefficient by using the SPSS program.

\section{Results}

The scores for BNT-1 and BNT-2 followed similar distributions (data not shown). The ANOVA and the subsequent mean comparisons clearly differentiated patients with dementia from patients without dementia and healthy individuals. As expected, patients with dementia had lower scores, while patients without dementia and the control group were not significantly different (Table 2). Differences between genders were significant for scores on BNT-2 and two of the abbreviated BNT versions (BNT12 and BNTOu11). Differences among language groups were significant for the Spanish MMSE, BNT-2 and the abbreviated version BNT12. Males scored significantly higher than females for all tests, although differences

Table 2. Mean comparison of the whole sample of elderly from the rural population of Ourense (northwestern Spain)

\begin{tabular}{|c|c|c|c|c|c|c|}
\hline FACTOR & SPANISH MMSE & BNT 2 ND & BNT 1 & BNT 15 & BNT 12 & BNT Oul 1 \\
\hline \multicolumn{7}{|l|}{ Gender } \\
\hline Female & $24.3 \pm 0.3$ & $34.8 \pm 0.9 b$ & $35.0 \pm 0.9$ & $9.6 \pm 0.3$ & $5.4 \pm 0.3 b$ & $5.2 \pm 0.3 b$ \\
\hline Male & $29.5 \pm 0.5$ & $38.1 \pm 1.3 \mathrm{a}$ & $37.4 \pm 1.3$ & $10.2 \pm 0.4$ & $7.8 \pm 0.4 \mathrm{a}$ & $7.1 \pm 0.4 \mathrm{a}$ \\
\hline \multicolumn{7}{|l|}{ Language } \\
\hline Bilingual & $24.8 \pm 0.6 \mathrm{ab}$ & $37.4 \pm 1.5 \mathrm{a}$ & $37.2 \pm 1.5$ & $10.0 \pm 0.4$ & $7.3 \pm 0.5 \mathrm{ab}$ & $6.5 \pm 0.5$ \\
\hline Spanish & $25.3 \pm 0.6 \mathrm{a}$ & $38.3 \pm 1.6 \mathrm{a}$ & $37.3 \pm 1.7$ & $10.3 \pm 0.5$ & $7.8 \pm 0.5 \mathrm{a}$ & $6.6 \pm 0.6$ \\
\hline Galician & $23.7 \pm 0.3 b$ & $33.7 \pm 0.8 b$ & $34.0 \pm 0.8$ & $9.4 \pm 0.2$ & $6.3 \pm 0.3 b$ & $5.5 \pm 0.3$ \\
\hline \multicolumn{7}{|l|}{ Diagnostic } \\
\hline Dementia & $21.1 \pm 0.6 b$ & $29.9 \pm 1.5 b$ & $29.8 \pm 1.5 b$ & $8.1 \pm 0.4 b$ & $5.1 \pm 0.5 b$ & $3.9 \pm 0.5 b$ \\
\hline Non dementia & $26.6 \pm 0.6 \mathrm{a}$ & $40.1 \pm 1.5 \mathrm{a}$ & $39.2 \pm 1.5 \mathrm{a}$ & $10.6 \pm 0.4 \mathrm{a}$ & $8.2 \pm 0.5 \mathrm{a}$ & $7.3 \pm 0.5 \mathrm{a}$ \\
\hline Control & $26.1 \pm 0.4 \mathrm{a}$ & $39.4 \pm 1.1 \mathrm{a}$ & $39.5 \pm 1.0 \mathrm{a}$ & $11.1 \pm 0.3 \mathrm{a}$ & $8.1 \pm 0.3 a$ & $7.3 \pm 0.4 \mathrm{a}$ \\
\hline Minimum-maximum & $13-30$ & $13-56$ & $13-56$ & $3-15$ & $1-12$ & $0-11$ \\
\hline
\end{tabular}

Means followed by the same letter are not significantly different from the other means of the same category, according to the least square means at $\mathrm{P}=0.05$. 
Table 3. Sensitivity and specificity for the shortened versions of the Boston Naming Test from Argentina (underlined), Andalusia (italics) and BNTOu11 (bold)

\begin{tabular}{|c|c|c|}
\hline NAME & SENSITIVITY & SPECIFICITY \\
\hline Tree & 0.02 & 0.99 \\
\hline Helicopter & 0.30 & 0.96 \\
\hline$\overline{\text { Broom }}$ & 0.05 & 1.00 \\
\hline Octopus & 0.28 & 0.94 \\
\hline$\overline{\text { Hanger }}$ & 0.14 & 0.97 \\
\hline Mask & 0.47 & 0.85 \\
\hline$\overline{\text { Racket }}$ & 0.28 & 0.88 \\
\hline Volcano & 0.79 & 0.50 \\
\hline$\overline{\text { Globe }}$ & 0.53 & 0.78 \\
\hline Crown & 0.40 & 0.87 \\
\hline Harmonica & 0.72 & 0.50 \\
\hline$\overline{\text { Rhinoceros }}$ & 0.79 & 0.45 \\
\hline Acorn & 0.53 & 0.67 \\
\hline Stilts & 0.86 & 0.56 \\
\hline Dominoes & 0.30 & 0.77 \\
\hline Cactus & 0.84 & 0.40 \\
\hline$\overline{\text { Escalator }}$ & 0.49 & 0.76 \\
\hline Hammock & 0.72 & 0.68 \\
\hline Lock & 0.33 & 0.94 \\
\hline$\overline{\text { Pyramid }}$ & 0.81 & 0.41 \\
\hline$\overline{\text { Muzzle }}$ & 0.60 & 0.90 \\
\hline$\overline{\text { Accordion }}$ & 0.30 & 0.92 \\
\hline Compass & 0.84 & 0.64 \\
\hline Scroll & 1.00 & 0.13 \\
\hline Tongs & 0.67 & 0.51 \\
\hline Yoke & 0.60 & 0.83 \\
\hline Palette & 0.91 & 0.12 \\
\hline$\overline{\text { Abacus }}$ & 1.00 & 0.01 \\
\hline Clock & 0.02 & 1.00 \\
\hline Swordfish & 0.72 & 0.65 \\
\hline
\end{tabular}

were not significant for half of them. Regarding language, Spanish speakers obtained higher scores than Galician monolinguals; bilinguals were not significantly different from the other monolingual groups except for BNT-2. None of the interactions was significant (data not shown).

The items of the BNT with specificity and sensitivity above 0.5 were selected to create a shortened battery of 11 pictures named BNTOu 11 (Table 3). Those items were: "Volcán" (Volcano), "Globo" (Globe), "Armónica" (Harmonica), "Bellota" (Acorn), "Zancos" (Stilts), "Hamaca" (Hammock), "Bozal" (Muzzle), "Compás" (Compass), "Pinzas" (Tongs), "Yugo" (Yoke), and "Pez Espada" (Swordfish). Among these 11 items, four were common with BNT12 (the Argentinian short version) and two with the BNT15 (the Andalusian version). These two items, Stilts and Muzzle, were common to the three abbreviated versions of BNT used with Spanish-speaking populations.
Table 4. Area under the ROC curve (AUC), standard error and confidence interval for five tests: MEC, both complete and the three shortened versions of BNT

\begin{tabular}{lll}
\hline TEST & AUC \pm SE & $\begin{array}{l}\text { CONFIDENCE } \\
\text { INTERVAL }\end{array}$ \\
\hdashline$\ldots \ldots \ldots \ldots \ldots \ldots \ldots \ldots \ldots \ldots \ldots \ldots \ldots$ \\
MEC & $0.866^{* *} \pm 0.037$ & $0.794-0.937$ \\
BNT-2 & $0.785^{* *} \pm 0.045$ & $0.696-0.874$ \\
BNT-1 & $0.779^{* *} \pm 0.045$ & $0.691-0.868$ \\
BNT15 & $0.799^{* *} \pm 0.042$ & $0.718-0.881$ \\
BNT12 & $0.772^{* *} \pm 0.047$ & $0.680-0.864$ \\
\hline
\end{tabular}

** Significant at $\mathrm{p}=0.01$

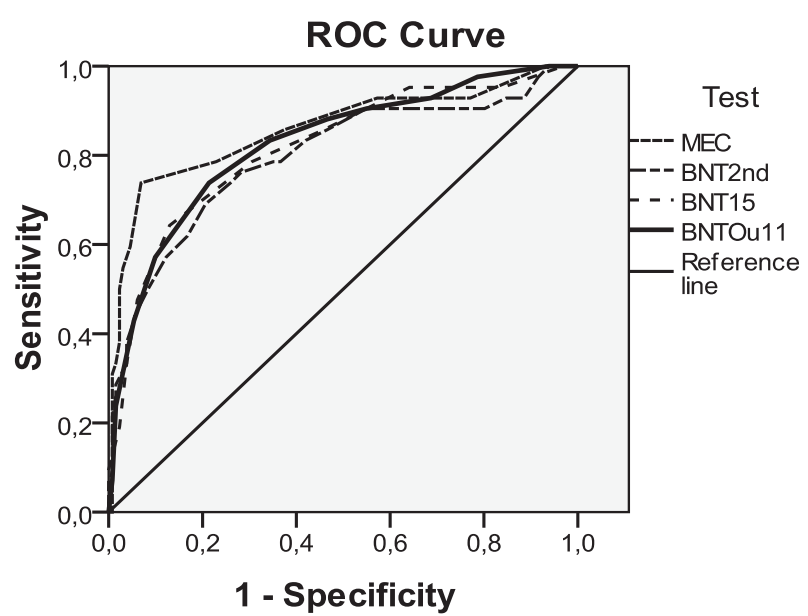

Figure 1. ROC curve of Spanish MMSE, the 60-item BNT2nd and two shortened versions of BNT.

The long BNT versions and the shortened ones had similar correlation coefficients to the Spanish MMSE, with values from 0.55 to 0.60 . BNT-1 and BNT-2 were highly correlated $\left(r^{2}=0.99\right)$, and the shortened versions had high positive and similar correlation coefficients to the long versions and between themselves with values from 0.83 and 0.92 .

ROC curves for Spanish MMSE and 60item and shortened BNT versions are shown in Figure 1. Areas under ROC curves (AUC) did not show statistically significant differences based on confidence intervals (Table 4); therefore, the AUC of BNTOu11 was comparable to that of the abbreviated and the 60 -item versions of BNT and to the Spanish version of the MMSE. Cronbach's $\alpha$ for BNTOu 11 was 0.784 ( $>0.7$ is broadly accepted as satisfactory), while for the Andalusian version this was 0.723 and for the Argentinian version 0.747. On the other hand, Cronbach's $\alpha$ for BNT-1 and BNT2 were 0.909 and 0.912 , respectively. Cronbach's $\alpha$ is expected to be higher for tests with more items. 


\section{Discussion}

In our sample, one third of the healthy individuals have BNT scores below the critical value of 36 points, and even though the control group had higher values than the dementia group, the BNT values of the control individuals were low (38 out of 60). These low scores can be explained by the low cultural level of the target population and by the different cultural background of our population, which clearly differ from the North American population for which the test was originally devised. The distribution of sensitivity and specificity showed that in our population many items in the BNT 60-item versions are easily recognized by most participants irrespectively of diagnosis, whereas others are never recognized either by cases or by controls. This finding encourages the development of specific shortened versions of the BNT, a similar rationale to that followed by Calero et al. (2002) and Serrano et al. (2001) in Andalusia and Argentina, respectively.

Gender differences on the Spanish MMSE or BNT scores have been reported previously (Lansing et al. 1999; Calero et al. 2002) and could be explained in our sample by the informal schooling of males due to migration (García-Caballero et al., 2006) or simply because of their exposure to wealthier environments during work outside the family farms. It is a well-known fact that black and white silhouette drawings, like the BNT's pictures, show cultural effects (Reis et al., 1998; 2006), a fact that could penalize women more than men. This effect should be taken into account in order to avoid a false diagnosis of anomia. The same rationale can be argued regarding the superior scores of bilinguals over monolinguals. Traditionally, Galician was spoken in everyday life, while Spanish was limited to formal contexts. During Franco's regime Galician was banned and therefore formal education in Galician was prohibited until more recent decades (GarcíaCaballero et al., 2007). Even though Galician and Spanish show a high degree of shared vocabulary (e.g. cow is "vaca" and comb is "peine" in both Spanish and Galician), many of the items on BNT (especially the least frequent) are accessible only in Spanish, the "school language" until 30 years ago. The intriguing question of whether bilingualism can provide a protective effect against dementia, as suggested by Bialystok et al. (2007) and Kavé et al. (2008), cannot be addressed with our current data.

The strategy for defining a specific shortened version based on independent cutting levels for sensitivity and specificity has been efficient because the BNTOul1 is shorter than the previous short versions and shows significant differences between the dementia and control groups. The discriminative power of the short versions is not significantly different. The three short versions share two items - Stilts and Muzzle - but the two versions specifically designed for Spanishspeaking populations share four, while BNT15, which was designed (randomly) for an English population, only shares two items, suggesting that short versions should be designed specifically for the target population.

The areas under ROC curves (AUC) did not show statistically significant differences (Table 4), indicating that AUC (0.814) was comparable to that of the BNT 60 -item versions $(0.785$ and 0.779 , respectively) and also to BNT12 (0.772) and BNT15 (0.799). Also, these values were not significantly different from the Spanish version of the MMSE (0.866). Concerning the internal consistency, the 60 -item versions of BNT had the highest values of Cronbach's $\alpha$, as expected, because the number of items is higher. Although Cronbach's $\alpha$ depends on the correlation among items and the number of items, among the shortened versions, the BNTOu11 has higher consistency but fewer items. Furthermore, when checking the Cronbach's $\alpha$ of the three short versions after removing one item at random, the $\alpha$ of BNTOu11 produced lower values than the original for any item, indicating that none of the items should be removed. By contrast, for the other versions, BNT15 and BNT12, $\alpha$ increased by removing one item. This result confirms that BNTOu 11 has higher internal consistency than the other short versions.

This research has some limitations. Even though we excluded the control participants with MMSE scores below 24, the control group could still include individuals with mild cognitive impairment or very mild dementia because the controls were not as thoroughly evaluated as the patients. The classes of sex and language were not similar among patients and controls, which could cause some bias in the analyses. In addition, our new shortened version BNTOu11 should be tested in an independent sample before replacing the complete versions of BNT for screening purposes.

In conclusion, our results support the idea that shortened versions of the BNT are at least as useful as the 60 -item versions for screening for language impairment in dementia, with the advantage of saving considerable time. Shortened versions have been created by removing those items that were irrelevant for anomia screening because many elders have never been exposed to them. Previous authors have demonstrated the convenience of replacing the 60 -item versions of the BNT with shortened ones specifically chosen for different target populations 
(Lansing et al., 1999; Serrano et al., 2001; Calero et al., 2002). The proposed short version BNTOu1 1 deserves some credit and further research to demonstrate its value as part of a battery for language screening in dementia among the rural community in Galicia.

\section{Conflict of interest}

None.

\section{Description of authors' roles}

M. C. Nebreda obtained most of the data and carried out the main part of the analysis and writing. A. García-Caballero, director of the project; designed and supervised the project and corrected the paper. E. Asensio assisted with data recording other than the BNT. P. Revilla carried out part of the statistical analysis and cooperated in the discussion and redaction of the text. M. Rodriguez-Girondo designed and performed some of the statistical analyses. R. Mateos supervised the project and corrected the paper.

\section{Acknowledgments}

The authors thank everyone who helped to carry out this research. We also thank the editor and reviewers for their useful suggestions for improving the paper.

This research was approved by the Ethics Committee of the Regional Government of Galicia.

\section{References}

American Psychiatric Association (2000). Diagnostic and Statistical Manual of Mental Disorders, 4th edition, text revision (DSM-IVTR). Washington DC: American Psychiatric Association.

Bialystok, E., Craik, F. I. M. and Freedman, M. (2007). Bilingualism as a protection against the onset of symptoms of dementia. Neuropsychologia, 45, 459-464.

Calero, M. D., Arnedo, M. L., Navarro, E., Ruíz-Pedrosa, M. and Carnero, C. (2002). Usefulness of a 15-item version of the Boston Naming Test in neuropsychological assessment of low-educational elders with dementia. Fournal of Gerontology: Psychological Sciences, 57, 187-191.

Feher, E. P., Mahurin, R. K., Doody, R. S., Cooke, N., Sims, J. and Pirozzolo, F. J. (1992). Establishing the limits of the Mini-mental State Examination of subtests. Archives of Neurology, 49, 87-92.

Folstein, M. F., Folstein, S. E. and McHugh, P. R. (1975). "Mini-mental state": a practical method for grading the cognitive state of patients for the clinician. Fournal of Psychiatric Research, 12, 189-198.
García-Caballero, A. et al. (2006). Validation of the Spanish version of the Addenbrooke's Cognitive Examination in a rural community in Spain. International Fournal of Geriatric Psychiatry, 21, 239-245.

García-Caballero, A. et al. (2007). Paradoxical recovery in a bilingual aphasic following right capsulo-putaminal infarction. Fournal of Geriatric Psychiatry and Neurology, 78, 89-91.

Goodglass, H. (2005). Evaluación de la afasia y de trastornos relacionados. Madrid: Editorial Médica Panamericana.

Goodglass, H. and Kaplan, E. (1986). Evaluacion de la afasia y de trastornos relacionados. Madrid: Editorial Médica Panamericana.

Goodglass, H., Wingfeld, A. and Hyde, M. R. (1998). The Boston corpus of aphasic naming errors. Brain and Language, 64, 1-27.

Kaplan, E. F., Goodglass, H. and Weintraub, S. (1978). The Boston Naming Test. Philadelphia: Lea \& Febiger.

Kavé, G., Eyal, N., Shorek, A. and Cohen-Mansfield, J. (2008). Multilingualism and cognitive state in the oldest old. Psychology and Aging, 23, 70-78.

LaBarge, E., Edwards, D. and Knesevish, J. (1986). Performance of normal elderly on the Boston Naming Test. Brain and Language, 27, 380-384.

Lansing, A. E., Ivnik, R. J., Cullum, C. M. and Randolph, C. (1999). An empirically derived short form of the Boston Naming Test. Archives of Clinical Neuropsychology, 1, 481-487.

Lobo, A. et al. (1999). Revalidación y normalización del Mini-Examen Cognoscitivo (primera versión en castellano del Mini-mental State Examination) en la población general geriátrica. Medicina Clínica (Barcelona), 112, 767774.

Mack, W. J., Freed, D. M., Williams, B. W. and Henderson, V. W. (1992). Boston Naming Test: shortened versions for use in Alzheimer's disease. Fournal of Gerontology: Psychological Sciences, 47, 154-158.

Martin, A. and Fedio, P. (1983). Word production and comprehension in Alzheimer's disease: the breakdown of semantic knowledge. Brain and Language, 19, 124141.

Paradis, M. and Elias, J. (1989). Test de afasia para bilingües, European Spanish Version. Hillsdale, NJ: Lawrence Erlbaum Associates.

Reis, A., Petersson, K. M., Castro-Caldas, A. and Ingvar, M. (1998). Formal schooling influences two- but not three-dimensional naming skills. Brain Cognition, 47, 397-411.

Reis, A., Faísca, L., Ingvar, M. and Petersson, K. M. (2006). Color makes a difference: two-dimensional object naming skills in literate and illiterate subjects. Brain and Cognition, 60, 49-54.

SAS Institute (2007). The SAS System. SAS Online Doc. HTML Format Version 8. Cary, NC: SAS Institute Inc.

Serrano, C., Allegri, R. F., Drake, M., Butman, J., Harris, P., Nagle, C. and Ranalli, C. (2001). Versión abreviada en español del test de denominación de Boston: su utilidad en el diagnóstico diferencial de la enfermedad de Alzheimer. Revista de Neurología, 33, 624-627.

Steel, R. D. G., Torrie, J. H. and Dickey, D. A. (1997). Principles and Procedures in Statistics: A Biometrical Approach, 3rd edn. New York: McGraw Hill. 
Tombaugh, T. N. and McIntyre, N. J. (1992). The Mini-mental State Examination: a comprehensive review. Fournal of the American Geriatrics Society, 40, 923-935.

Weintraub, S. (2000). Neuropsychological assessment of mental state. In M. M. Mesulam (ed.), Principles of Behavioral and Cognitive Neurology (pp. 121-173) New York: Oxford University Press.
Welch, L. W., Doineau, D., Johnson, S. and King, D. (1996). Educational and gender normative data for the Boston Naming Test in a group of older adults. Brain and Language, 53, 260-266.

Williams, B. W., Mack, W. and Henderson, V. (1989). Boston Naming Test in Alzheimer's disease. Neuropsychologia, 27, 1073-1079. 